\title{
Polygonum viviparum L. induces vasorelaxation in the rat thoracic aorta via activation of nitric oxide synthase in endothelial cells
}

\author{
Ming-Long Chang ${ }^{1 \dagger}$, Jung-Su Chang ${ }^{2 \dagger}$, Wen-Yu Yu ${ }^{1}$, Khoot-Peng Cheah ${ }^{1}$, Joe-Sharg Li ${ }^{1}$, Hui-Wen Cheng ${ }^{3}$ \\ and Chien-Ming $\mathrm{Hu}^{1,4,5^{*}}$
}

\begin{abstract}
Background: In the past several decades, Polygonum viviparum L. (PV) was reported to have antibacterial, antiulcer, antioxidant, antitumor, anti-inflammatory, and antiarthritic properties. The anti-inflammatory pathway was recently elucidated through cytosolic nuclear factor E2-related factor 2 ( Nrf2) activation and heme oxygenase (HO)-1 protein expression. PV is a perennial herb and widely distributed in high-elevation mountain regions, such as the Tibetan Plateau. In Tibetan traditional medicine, PV is usually used to boost the blood circulation to dissipate blood stasis. Therefore, this study focused on how PV improves the vascular circulation and acts on vascular tissues.

Methods: In this study, we isolated aortas from Sprague-Dawley rats (male, weight about $250 \sim 350 \mathrm{~g}$ ), and detected the effects of PV on phenylephrine (PE)-induced contraction and cyclic guanosine 3',5'-monophosphate (cGMP) formation using aortic rings. In addition, human umbilical vein endothelial cells (HUVECs) were used to exam nitric oxygen (NO) synthase (NOS) activity by directly measuring NO production in the culture medium. Endothelial (e) NOS phosphorylation, and cytosolic Nrf2 and HO-1 expressions were measured using a Western blot analysis.

Results: PV dose-dependently relaxed PE-induced contractions in endothelial-intact but not -denuded aorta. The concentration to produce $50 \%$ relaxation was $22.04 \pm 1.77 \mu \mathrm{g} / \mathrm{ml}$. PV-induced vasorelaxation was markedly blocked by pretreatment with $N^{G}$-nitro-_-arginine methyl ester (L-NAME), an NOS inhibitor, methylene blue (MB), a guanylyl cyclase inhibitor, and hemoglobin, an NO scavenger. PV increased CGMP formation; however, this effect was also suppressed by co-pretreatment with L-NAME, MB, hemoglobin, and $\mathrm{Ca}^{2+}$-free medium. In HUVECS, PV increased NO formation, which was greatly attenuated by NOS inhibitors (L-NAME and L-NMMA) and by removing extracellular $\mathrm{Ca}^{2+}$ and chelating intracellular $\mathrm{Ca}^{2+}$ with BAPTA-AM. In addition, PV promoted eNOS phosphorylation, Nrf2 degradation, and HO-1 protein expression according to a Western blot analysis.

Conclusions: The results suggest that PV possesses vasorelaxing action in an endothelium-dependent manner and works through activating $\mathrm{Ca}^{2+} /$ calmodulin- dependent $\mathrm{NO}$ synthesis; when $\mathrm{NO}$ is released and then transferred to smooth muscle cells, NO activates guanylyl cyclase and increases cGMP formation, ultimately resulting in vasorelaxation. Thus, PV can be considered for application as a potential therapeutic approach for vascular-associated disorders.
\end{abstract}

Keywords: Polygonum viviparum L, Aorta, Vasorelaxation, cGMP, eNOS, HUVECS

\footnotetext{
* Correspondence: sunpowerhu@tmu.edu.tw

${ }^{\dagger}$ Equal contributors

${ }^{1}$ Emergency Department, Taipei Medical University Hospital, 252 Wu-Xing

Street, Taipei 110, Taiwan

${ }^{4}$ Department of General Medicine, School of Medicine, College of Medicine,

Taipei, Taiwan

Full list of author information is available at the end of the article
} 


\section{Background}

Polygonum viviparum L. (PV), a perennial herb, belongs to the Polygonaceae family and is extensively distributed in high-elevation mountain region, including the Alps, Carpathians, Pyrenees, Caucasus Mountains, and the Tibetan Plateau [1,2]. The common names of PV are bistort, serpent-grass, and viviparous knotweed [3]. PV is a perennial herb that arises from a short, thickened rhizome that appears massive, distorted or uncinated. The stem, which ranges from 10 to $30 \mathrm{~cm}$ in height and terminates in a narrow, dense flowering spike, is simple, erect and smooth and bears few leaves. The best survey period lasts from approximately late June to early September [4]. In traditional folk medicine, PV is used to treat pharyngitis, dysentery, and gastrointestinal disorders [5]. The rhizome and root of PV are reported to possess excellent potency for curing bronchitis, piles, wounds, ulcers, vomiting, and biliousness [6-8]. From the literature over several decades, the major constituents of PV perhaps involve volatile oils [9], flavonoids, flavone glycosides [10-13], gallic acid, saponins, and tannins [14-16]. In addition, PV was demonstrated to possess efficacious bioactive effects, including antibacterial [11,17], antiulcer [7], antioxidant [8,18], antitumor $[9,19]$, anti-inflammatory, and antiarthritic properties [20].

In our previous study, we demonstrated that PV has anti-inflammatory actions in macrophages, possibly acting through cytosolic nuclear factor E2-related factor 2 (Nrf2) activation to express heme oxygenase (HO)-1 protein [4]. On the other hand, especially in Tibetan traditional medicine, PV is usually used to boost the blood circulation to dissipate blood stasis [21]. Consequently, we wanted to determine how PV improves the vascular circulation, and what effect PV has on vascular tissues. In this study, the effect of PV on the thoracic aorta isolated from rats was examined.

\section{Methods}

\section{Plant material}

Polygonum viviparum L. (PV) was obtained from Tibet. Its authenticity was confirmed by $\mathrm{Dr}$ Shin-Ming $\mathrm{Ku}$ (Herbarium, Biodiversity Research Center, Academia Sinica, Taipei, Taiwan). The herb (PV 100 g) was extracted with $3 \mathrm{~L}$ of 2-propanol for 7 days, then the extract was filtered and centrifuged at $13000 \times g$ for $10 \mathrm{~min}$. The extract supernatant was passed through a $0.22 \mu \mathrm{m}$ sterile filter (Millipore, Billerica, MA, USA) and first concentrated using a vacuum rotary evaporator (Yamato, Tokyo, Japan) at $40^{\circ} \mathrm{C}$. Normally, $8.76 \mathrm{~g}$ of dried powder could be obtained from $100 \mathrm{~g}$ of PV. The dried extract yield from the crude material was thus approximately $8.76 \%[4]$.

\section{Drugs and chemicals}

Phenylephrine (PE), acetylcholine (Ach), $N^{\mathrm{G}}$-nitro-L-arginine methyl ester (L-NAME), $N^{G}$-monomethyl-L-arginine acetate (L-NMMA), methylene blue (MB), hemoglobin $(\mathrm{Hb})$, and all chemicals of the Krebs solution were from Sigma Chemical (St. Louis, MO, USA). Culture materials (M199 medium, fetal bovine serum (FBS), and trypsinEDTA) were obtained from Life Technologies (Gibco, Grand Island, NY, USA). Endothelial cell growth supplement (ECGS) was purchased from Millipore (Billerica, MA, USA). A cyclic guanosine $3^{\prime}, 5^{\prime}$-monophosphate (cGMP) enzyme immunoassay kit was purchased from R \& D System (Minneapolis, MN, USA). All other agents of cell culture were obtained from Sigma Chemical.

\section{Preparation of rat aorta and tension recording ex vivo}

Male Sprague-Dawley rats weighing about $250 \sim 350 \mathrm{~g}$ were purchased from BioLASCO (Taipei, Taiwan). All animal procedures were approved by the institutional animal care and using committee of Taipei Medical University. Animals were housed in polycarbonate cages in a room at $22 \pm 2^{\circ} \mathrm{C}$ on a 12-h light-dark cycle. The procedure described by $\mathrm{Hu}$ et al. [22] was used to isolate rat aortic rings. When the experiment began, the rats were sacrificed by exsanguination from the carotid artery under lose consicousness by knocking medulla; the thoracic aorta of rats was carefully removed, and the fat and tissue were dissected away in normal Krebs' buffer at an adjusted $\mathrm{pH}$ of 7.4. The composition of this buffer was as follows: $118.5 \mathrm{mM} \mathrm{NaCl}$, $4.8 \mathrm{mM} \mathrm{KCl}, 1.2 \mathrm{mM} \mathrm{MgSO}, 1.2 \mathrm{mM} \mathrm{KH}_{2} \mathrm{PO}_{4}$, $2.5 \mathrm{mM} \mathrm{NaHCO}, 11.1 \mathrm{mM}$ glucose, and $2.5 \mathrm{mM}$ $\mathrm{CaCl}_{2}$. The aorta was cut into rings about $5 \mathrm{~mm}$ long in Krebs buffer which was constantly gassed with $95 \%$ $\mathrm{O}_{2}+5 \% \mathrm{CO}_{2}$ at $37 \pm 0.5^{\circ} \mathrm{C}$. Two "L"-type stainless steel hooks were inserted into the aortic lumen; one side was fixed in the bottom bath and the other side was connected to a force transducer using a cotton thread. The aortic rings were equilibrated in Krebs buffer and maintained under a 1-g tension for $60 \sim 90 \mathrm{~min}$, with three changes of buffer, before the experimental procedures began. Contractions were recorded isometrically via an iWorx FT-302 force transducer connected to an iWorx $304 \mathrm{~T}$ recorder (iWorx System, Dover NH, USA). In denuded aorta, the endothelium was removed by rubbing with a cotton ball, and the absence of AChinduced relaxation was taken as an indicator of successful denudation. After PE-induced contraction and ACh-induced relaxation twice, PV (1, 3, 10, 30, 100 and $300 \mu \mathrm{g} / \mathrm{ml}$ ) was treated after PE-induced contraction. The effects of PV as percentage of relaxation considering the maximum contraction elicited by phenylephrine in preparations with at least $80 \%$ of relaxation to $\mathrm{ACh}$. 


\section{Cyclic guanosine 3',5'-monophosphate (cGMP) measurement}

Rat aorta cGMP was analyzed using the method of Kauffman et al. [23]. Briefly, the aorta was immediately isolated from a rat, and cut into segments of about $20 \mathrm{mg} /$ tissue. First, the rat aortic rings were pre-incubated in Krebs' solution with 3-isobutyl-1-methylxathine (IBMX, $10 \mu \mathrm{M})$ for $5 \mathrm{~min}$. Then, the aortic segments were placed in $\mathrm{Ca}^{2+}$-free Krebs' (EGTA $2.5 \mathrm{mM}$ ) buffer or pretreatment inhibitors of L-NAME $(50 \mu \mathrm{M})$ and MB $(10 \mu \mathrm{M})$ for $10 \mathrm{~min}$; then PV $(100 \mu \mathrm{g} / \mathrm{ml})$, sodium nitroprusside (SNP, $10 \mu \mathrm{M})$, and $\mathrm{ACh}(10 \mu \mathrm{M})$, as positive reagents, were added for a further $2 \mathrm{~min}$. After incubation with PV and $\mathrm{ACh}$, the aortic segments were rapidly frozen in liquid nitrogen and stored at $-80^{\circ} \mathrm{C}$ until homogenized in $0.5 \mathrm{ml}$ of $10 \%$ trichloroacetic acid using a motor-driven glass homogenizer. The homogenate was centrifuged at $10,000 \times g$ for $5 \mathrm{~min}$, and the supernatant was removed and extracted three times with $1.5 \mathrm{ml}$ of water-saturated diethyl ether. The cGMP content was then assayed using enzyme immunoassay kits ( R \& D System, Minneapolis, $\mathrm{MN}$, USA). Protein was measured by dissolving the trichloroacetic acid precipitate in $1 \sim 2 \mathrm{ml}$ of $5 \mathrm{~N} \mathrm{NaOH}$ followed by analysis using the method of Lowry et al. [24].

\section{Cell culture}

Human umbilical vein endothelial cells (HUVECs, confluent second passage, $\mathrm{P}=2$ ) were purchased from the Bioresource Collection and Research Center (BCRC), Food Industry Research and Development Institute (Hsinchu, Taiwan). Cells were grown at $37 \pm 0.5^{\circ} \mathrm{C}$ in a humidified $5 \% \mathrm{CO}_{2}$ atmosphere in M199 medium (pH 7.4) supplemented with $10 \% \mathrm{FBS}, 25 \mathrm{U} / \mathrm{ml}$ heparin, $30 \mu \mathrm{g} / \mathrm{ml}$ ECGS, $2 \mathrm{mM}$ glutamine, $1.5 \mathrm{~g} / \mathrm{l} \mathrm{NaHCO}_{3}, 10,000$ units/l of penicillin, and $100 \mathrm{mg} / \mathrm{l}$ of streptomycin. Culture plates were coated with $1 \%$ gelatin before use. Confluent cells were detached by trypsin-EDTA (0.05\%: $0.02 \%, \mathrm{v} / \mathrm{v})$, and cells from passages 3 to 7 were used in the experiment.

\section{Determination of nitric oxide (NO) production}

HUVECs $\left(5 \times 10^{5}\right.$ cells/well) in 6-well plates were incubated with or without various concentrations of PV (10, 30 , and $100 \mu \mathrm{g} / \mathrm{ml})$ and $\mathrm{ACh}(30 \mu \mathrm{M})$, as a positive control, for $1 \mathrm{~h}$. The supernatants of conditioned cells were deproteinized by zinc-sulfate $(30 \%, \mathrm{v} / \mathrm{v})$ and passed through a copper cadmium reduction column to reduce $\mathrm{NO}_{3}{ }^{-}$to $\mathrm{NO}_{2}{ }^{-}$[25]. As an indicator of $\mathrm{NO}$ production, the nitrite concentration in the culture medium was determined using the Griess reagent, as previously described [26]. The culture supernatant $(100 \mu \mathrm{l})$ was mixed with $100 \mu \mathrm{l}$ of the Griess reagent (1\% sulfanilamide and $0.1 \%$ $\mathrm{N}$-1-naphthyl ethylenediamine) for $10 \mathrm{~min}$, and then the chromophoric azo-derivative molecule's absorbance was measured in a microplate reader at $540 \mathrm{~nm}$. Fresh culture medium was used as the blank in all experiments. A range of dilutions of sodium nitrite $\left(\mathrm{NaNO}_{2}\right)$ was used to create a standard curve with the amount of nitrite in each sample. The final NO production was expressed as $\mu \mathrm{mol} / \mathrm{l}$ $(\mu \mathrm{M})$.

\section{Preparation of total cell lysates}

HUVECs $\left(5 \times 10^{5}\right.$ cells/well $)$ in 6-well plates were incubated with or without concentrations of PV $(3,10$, and $30 \mu \mathrm{g} / \mathrm{ml})$ or $\mathrm{ACh}(30 \mu \mathrm{M})$ for 0.5 or $24 \mathrm{~h}$. Total cell lysates were obtained using a lysis buffer $(250 \mathrm{mM}$ Tris$\mathrm{HCl}$ (pH 6.8), 1\% Triton-100, 0.1\% sodium dodecylsulfate (SDS), $1 \mathrm{mM} \mathrm{Na}_{3} \mathrm{VO}_{4}, 1 \mathrm{mM}$ EDTA, $5 \mathrm{mM}$ sodium fluoride, $1 \mathrm{mM}$ PMSF, and $1 \mathrm{mg} / \mathrm{ml}$ leupeptin), and cell debris was removed using a centrifuge at $10,000 \times g$ for $10 \mathrm{~min}$ at $4^{\circ} \mathrm{C}$ and stored at $-80^{\circ} \mathrm{C}$ until required. The protein content of the cell lysates was determined using the Bradford assay [27].

\section{Western blot analysis}

Equal amounts of cell lysates $(30 \mu \mathrm{g})$ were electroblotted onto a nitrocellulose membrane (Millipore), following separation using $8 \% \sim 12 \%$ SDS-polyacrylamide gel electrophoresis (PAGE). The blot was probed using a primary antibody against p-eNOS, total-eNOS (Millipore), Nrf2, HO-1, and $\beta$-actin (Santa Cruz Biochemicals, Santa Cruz, CA, USA). The intensity of each band was quantified using density analysis software (Biospectrum 500 Imaging System; Vision Works LS 6.5.2v, UK), and the density ratio represented the relative intensity of each band against controls in each experiment.

\section{Data and statistical analyses}

Results of all experiments are expressed as the mean \pm S.E. of multiple experiments $(n \geq 3)$. Data were compared using a one-way analysis of variance (ANOVA) with a post-hoc Bonferroni analysis when applicable, and $p$ values of $<0.05$ were considered statistically significant. Values of $50 \%$ effective concentration $\left(\mathrm{EC}_{50}\right)$ were calculated and obtained from 5 regression lines; each regression line was constructed from $3 \sim 5$ points. Values of inhibition of these points ranged $20 \% \sim 80 \%$.

\section{Results}

\section{PV-induced rat aortic relaxation}

The vasorelaxing effect of $\mathrm{PV}$ was examined on $\mathrm{PE}$ $(3 \mu \mathrm{M})$-precontracted rat aorta. Data show (Figure 1A) that PE induced a rapid phasic contraction, followed by a tonic contraction lasting for least $10 \mathrm{~min}$ in both intact (endothelium-undamaged) and denuded (endotheliumremoved) aorta. Treatment with ACh $(10 \mu \mathrm{M})$ caused relaxation in intact but not denuded aorta. PV relaxed PEinduced contractions in intact but not denuded aorta, as shown in Figure 1B. As shown in Figure 1C, the relaxing 
A

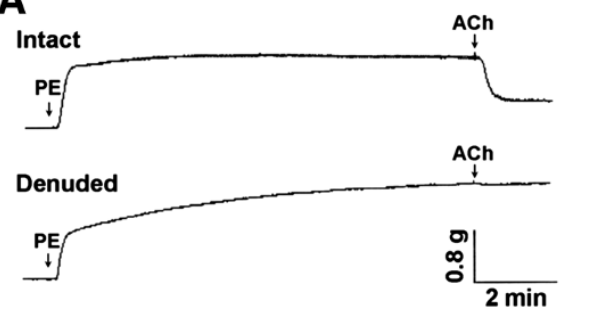

B

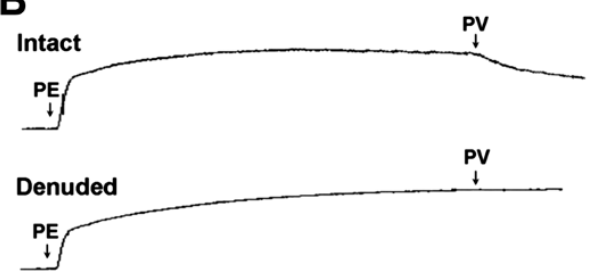

C

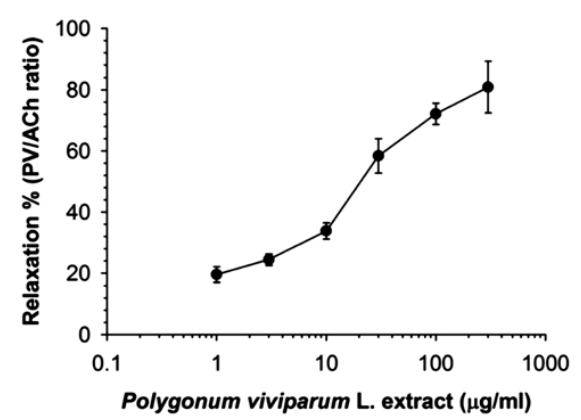

Figure 1 Relaxation effect of Polygonum viviparum L. (PV) in isolated rat thoracic aorta. The aorta was removed from a rat, and fat and tissue were carefully dissected away in normal $37^{\circ} \mathrm{C}$ Krebs solution. Phenylephrine (PE) at $3 \mu \mathrm{M}$ induced a transient phasic contraction followed by tonic contraction, which lasted at least $10 \mathrm{~min}$ in intact or endothelial-denuded aorta. Acetylcholine (ACh) at $10 \mu \mathrm{M}$ induced relaxation in intact (A, upper trace) but not denuded (A, lower trace) aorta. PV at $100 \mu \mathrm{g} / \mathrm{ml}$ relaxed PE-precontracted intact (B, upper trace) but not denuded (B, lower trace) aorta. (C) Concentration-response curve of vasorelaxation caused by PV on PE-precontracted rat intact aorta. Data are expressed as the mean \pm standard error of the mean (S.E.M.) ( $n \geq 5$ animals per time point).

responses of PV-induced contractions occurred in a dose-dependent manner. The $\mathrm{EC}_{50}$ value was $22.04 \pm$ $1.77 \mu \mathrm{g} / \mathrm{ml}$. The data indicated that PV might be responsible for the endothelium-dependent vasorelaxation.

\section{NO synthase (NOS), a guanylyl cyclase inhibitor, and an NO scavenger suppressed PV-induced vasorelaxation}

To elucidate endothelium-dependent PV-induced vasorelaxation, whether $\mathrm{NO}$ is involved in PV-induced vasorelaxation was further investigated. As shown in Figure 2, $10 \mu \mathrm{M}$ ACh typically relaxed PE-induced vasocontraction in endothelial-intact aorta (trace A). As shown trace B in Figure 2, PV also exhibited vasorelaxation that was similar to ACh's typical action in intact aorta. Pretreatment with $50 \mu \mathrm{M}$ L-NAME (an NOS inhibitor) did not influence PEinduced vasocontractions, but PV-induced vasorelaxation was suppressed (trace C). Likewise, as shown in traces D and E, PV-induced vasorelaxation was suppressed by pretreatment with $5 \mu \mathrm{M} \mathrm{Hb}$ (an $\mathrm{NO}$ scavenger) and $10 \mu \mathrm{M}$ MB (a guanylyl cyclase inhibitor).

\section{Formation of cGMP was elevated by treatment with PV in rat aorta}

cGMP formation was measured to confirm whether guanylyl cyclase activation participates in PV-induced vasorelaxation in the rat aorta. Aortic rings were divided into 5 groups: intact, denuded, L-NAME pretreatment, MB pretreatment, and $\mathrm{Ca}^{2+}$-free Krebs buffer. As shown in Table 1, the cGMP content of intact aorta significantly increased after treatment with $10 \mu \mathrm{M}$ ACh and $10 \mu \mathrm{M}$ SNP. However, ACh did not increase cGMP formation in the denuded aorta. In this experimental model, we found that PV's effect was similar to that of Ach which induced an increase in cGMP formation in intact but not denuded aorta. In addition, increases in the PV-induced cGMP content were suppressed by pretreatment with $50 \mu \mathrm{M}$ L-NAME, $10 \mu \mathrm{M} \mathrm{MB}$, or $\mathrm{Ca}^{2+}$-free medium. Therefore, these results further supported that NOS and guanylyl cyclase activities, and extracellular $\mathrm{Ca}^{2+}$ are involved in PV-induced vasorelaxation in the aorta.

\section{PV increased NO production}

To confirm NOS's activity, NO production was directly investigated in cultured medium of HUVECs using the Griess reagent. As shown in Figure 3, NO production dose-dependently increased after treatment with 3, 10, 30, and $100 \mu \mathrm{g} / \mathrm{ml} \mathrm{PV}$ in HUVECs for $1 \mathrm{~h}$. ACh was used as a positive control. As shown in Table 2, increases in PV- and ACh-induced NO production were attenuated by treatment with the NOS inhibitors, L-NAME and L-NMMA [28]. In addition, after removal of intercellular $\mathrm{Ca}^{2+}$ by treatment with EGTA or chelation of intracellular $\mathrm{Ca}^{2+}$ by treatment with 1,2-bis (2-aminophenoxy) ethane$\mathrm{N}, \mathrm{N}, \mathrm{N}$, N'-tetraacetic acid (BAPTA-AM, increases) in $\mathrm{PV}$ - and ACh-induced NO production were completely inhibited. These results suggest that influx of extracellular $\mathrm{Ca}^{2+}$ is indeed involved in the PV-activated NOS pathway.

\section{PV induced eNOS phosphorylation, cytosolic Nrf2 degradation, and HO-1 protein expression} To elucidate the time coures of PV's effect in HUVECs, the cells were treated with various concentrations of PV 


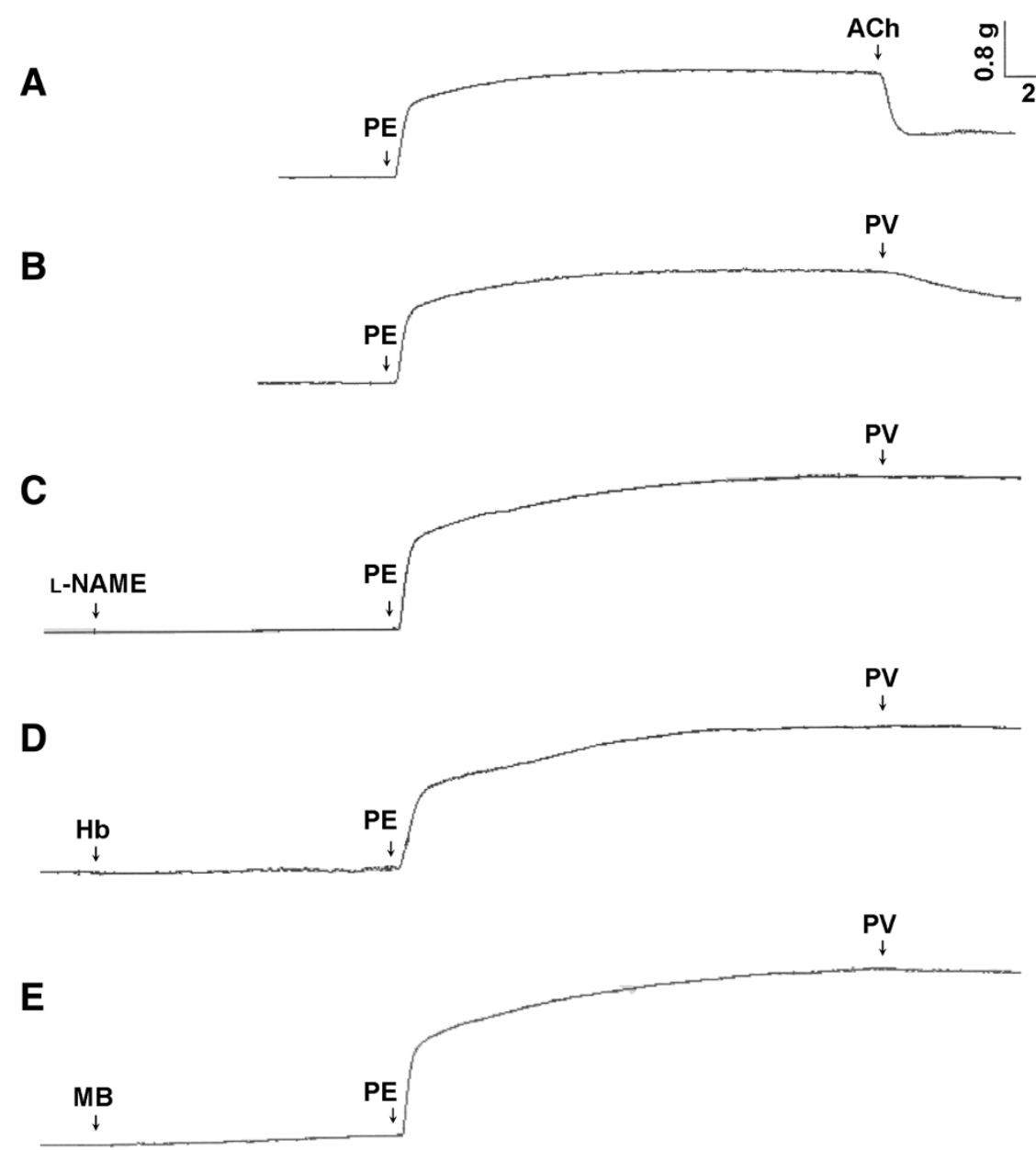

Figure 2 Effect of an nitric oxide (NO) synthase (NOS) inhibitor, NO scavenger, and guanylyl cyclase inhibitor on Polygonum viviparum (PV)-induced relaxation in isolated rat aorta. Acetylcholine (ACh) at $10 \mu \mathrm{M}$ and $100 \mu \mathrm{g} / \mathrm{ml} \mathrm{PV}$ (traces $\mathbf{A}$ and $\mathbf{B}$, respectively) were treated after $3 \mu \mathrm{M}$ phenylephrine (PE)-induced vasocontraction reached the maximal force in intact aorta. Prior to the addition of $100 \mu \mathrm{g} / \mathrm{ml} \mathrm{PV}$, the aorta was pretreated with $50 \mu \mathrm{M}$ L-NAME (trace $\mathbf{C}$ ), $5 \mu \mathrm{M}$ hemoglobin ( $\mathrm{Hb}$ ) (trace $\mathbf{D}$ ), and $10 \mu \mathrm{M}$ methylene blue (MB) (trace $\mathbf{E}$ ) for 6 min followed by the addition of PE. Each experiments was conducted in aortic rings of at least 5 animals.

$(3,10$, and $30 \mu \mathrm{g} / \mathrm{ml})$ for 0.5 or $24 \mathrm{~h}$. Cells were harvested by lysis buffer, and total cell lysates were collected; eNOS phosphorylation, cytosolic Nrf2 degradation, and HO-1 protein levels were determined by a Western immunoblot analysis. As shown in Figure 4A, treatment of HUVECs with PV for 30 min resulted in marked phosphorylation of eNOS in a dose-dependent manner, but the total eNOS protein did not increase. However, the phospho-eNOS level slightly decreased after treatment with PV for $24 \mathrm{~h}$ compared to treatment with PV for $30 \mathrm{~min}$. Treatment

Table 1 Effects of Polygonum viviparum (PV) on cyclic guanosine 3', 5'-monophosphate (cGMP) formation by the rat aorta

\begin{tabular}{lcccc}
\hline & \multicolumn{3}{c}{ cGMP (pmol/mg protein) } \\
\cline { 2 - 5 } & Intact & Denuded & L-NAME 50 $\mu$ M & MB 10 $\mu$ M \\
\hline Control & $0.53 \pm 0.08$ & - & - & - \\
SNP $10 \mu \mathrm{M}$ & $3.45 \pm 0.56^{*}$ & - & - & - \\
ACh $10 \mu \mathrm{M}$ & $3.21 \pm 0.42^{*}$ & $0.60 \pm 0.18$ & $0.70 \pm 0.09$ & $0.52 \pm 0.12$ \\
PV $100 \mu \mathrm{g} / \mathrm{ml}$ & $3.18 \pm 0.74^{*}$ & $0.57 \pm 0.13$ & $0.54 \pm 0.09$ & $0.66 \pm 0.07$
\end{tabular}

After pretreatment with $10 \mu \mathrm{M}$ IBMX for 5 min, aortic segments were replaced in $\mathrm{Ca}^{2+}$-free Krebs' $(2.5$ mM EGTA) buffer or treatment with inhibitors of L-NAME and methylene blue (MB) for $10 \mathrm{~min}$ and then sodium nitroprusside (SNP), acetylcholine (ACh) and PV were added for another 2 min. The aortic rings were immersed in liquid nitrogen to stop the reaction. CGMP formation were measured. Data are expressed as the mean \pm standard error of the mean (S.E.M) of more than 5 individual experiments. - , not determined. ${ }^{*} p<0.05$ indicates a significant difference from the control. 


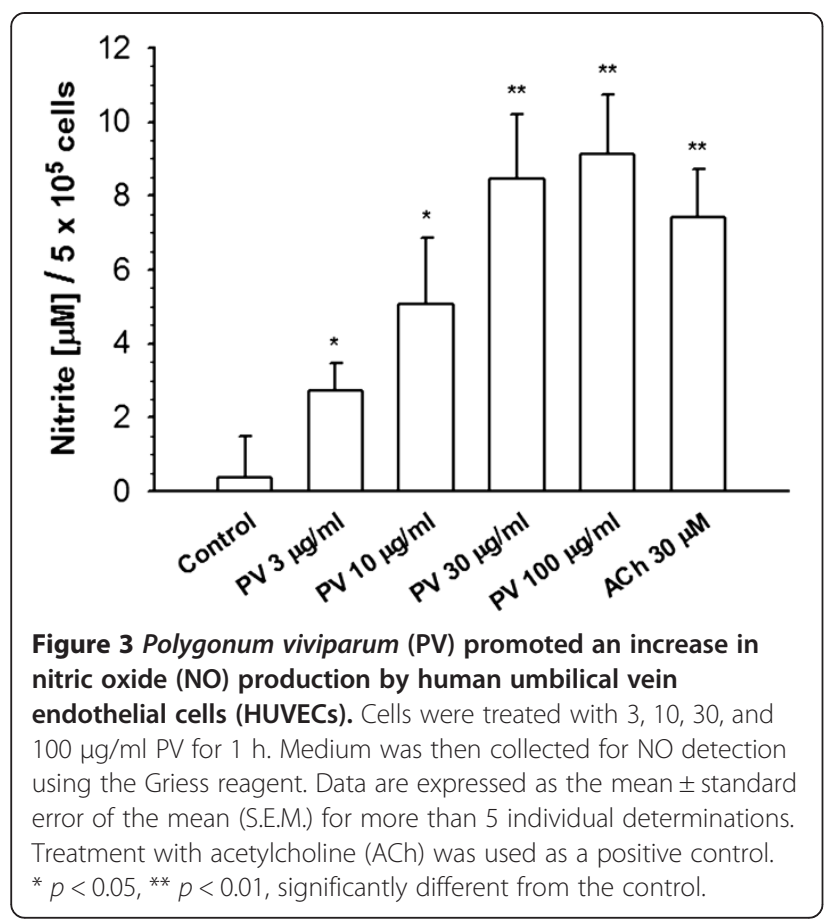

with ACh was used as a positive control. In addition, PV increased cytosolic Nrf2 degradation and HO-1 protein expression. As shown in Figure 4B, it is clear that the density ratio of phosphor-eNOS, cytosolic Nrf2 degradation and HO- 1 were elevated by PV in the quantitative determination.

\section{Discussion}

In this study, effects of PV were investigated on rat aorta ex vivo and on HUVECs in vitro. We explored the potential involvement of eNOS activation in vasorelaxation by PV. First, we found that PV dose-dependently induced vasorelaxation in PE-precontracted aorta in an endothelium-dependent manner (Figure 1). It is well known that NO was first discovered in 1980 as an endothelium-

Table 2 Effects of Polygonum viviparum (PV) on nitric oxide (NO) production by human umbilical vein endothelial cells (HUVECs)

\begin{tabular}{|c|c|c|c|}
\hline & \multicolumn{3}{|c|}{ Nitrite $[\mu \mathrm{M}] / 5 \times 10^{5}$ cells } \\
\hline & Blank & PV $(30 \mu \mathrm{g} / \mathrm{ml})$ & ACh $(30 \mu \mathrm{M})$ \\
\hline Blank & $0.378 \pm 0.559$ & $8.445 \pm 0.878$ & $7.412 \pm 0.661$ \\
\hline L-NAME $(50 \mu \mathrm{M})$ & $0.631 \pm 0.518$ & $2.073 \pm 0.244^{* *}$ & $1.066 \pm 0.165^{\# \#}$ \\
\hline L-NMMA $(50 \mu M)$ & $0.476 \pm 0.483$ & $2.232 \pm 0.383^{* *}$ & $1.154 \pm 0.397^{\# \#}$ \\
\hline $\mathrm{Ca}^{2+}$-free & $0.505 \pm 0.442$ & $0.668 \pm 0.324^{* *}$ & $0.964 \pm 0.352^{\# \#}$ \\
\hline BAPTA-AM $(20 \mu \mathrm{M})$ & $0.432 \pm 0.378$ & $0.584 \pm 0.460^{* *}$ & $0.511 \pm 0.369^{\# \#}$ \\
\hline
\end{tabular}

HUVECs were incubated with PV and acetylcholine (ACh) for $1 \mathrm{~h}$, and then the culture medium was collected for NO detection with the Griess reagent. $\mathrm{Ca}^{2+}$-free medium contained $2.5 \mathrm{mM}$ EGTA. BAPTA-AM chelates intracellular $\mathrm{Ca}^{2+}$. Data are expressed as the mean \pm standard error of the mean (S.E.M) for more than 5 individual experiments. ${ }^{* *} p<0.01$ indicates a significant difference from PV alone. ${ }^{\# \#} p<0.01$ indicates a significant difference from $\mathrm{ACh}$ alone. derived relaxing factor [29] and as a key control of vascular homeostasis [30]. NO is a soluble gas and is synthesized from the amino acid L-arginine by a family of enzymes called NOSs [31]. NOS activity can be inhibited by NOS blockers through a mechanism that competes with L-arginine for the substrate-binding site on NOS, such as L-NAME and L-NMMA [32,33], and the NO is caught by $\mathrm{NO}$ scavengers, such as $\mathrm{Hb}$ [34]. In blood vessels, eNOS converts L-arginine to L-citrulline and NO. Afterwards, NO can diffuse into both the vessel lumen and wall which activates soluble guanylate cyclase, leading to the intracellular accumulation of cGMP [35]. However, soluble guanylate cyclase activity is inhibited by some agents, such as MB [32]. In this study, we found that the vasorelaxation by PV could be suppressed by pretreatment with an NOS inhibitor (L-NAME), a guanylyl cyclase inhibitor (MB), and an NO scavenger ( $\mathrm{Hb}$ ) (Figure 2). These results indicate that the formation of $\mathrm{NO}$ and cGMP respectively involves activation of NOS and guanylyl cyclase. Further direct evidence was provided by measuring cGMP in the rat aorta (Table 1). Results showed that PV increased cGMP accumulation, and this effect was suppressed by pretreatment with L-NAME and MB (Figure 5).

Normally, homeostasis of the vessel wall is regulated by endothelial cells that are able to relax vascular smooth muscle cells. Under general physiological conditions, the dominant NOS isoform in the vasculature is eNOS [36]. In order to elucidate whether or not the effect of PV on the rat aorta is through activating eNOS-caused vasorelaxation, we further investigated the effects of PV on HUVECs. We found that NO production significantly increased after treatment with PV in HUVECs, and this increased NO production was inhibited by pretreatment with L-NAME and L-NMMA. In addition, we demonstrated that PV could promote eNOS phosphorylation, cytosolic Nrf2 degradation, and $\mathrm{HO}-1$ protein expression (Figure 4) by HUVECs. It is well known that eNOS can be regulated by multiple phosphorylation sites at tyrosine, serine, and threonine residues [36]. Fulton et al. reported that phosphorylation of Tyr83 regulates the ability of eNOS to produce NO [37]. Heiss et al. reported that activating Nrf2 can elevate the bioavailability of NO by triggering eNOS phosphorylation and reducing eNOS protein expression by HUVECs [38]. The nuclear factor E2-related factor 2 (Nrf2) play a critical role by interacting with cognate DNA-binding domains in the HO-1 promoter to up-regulate ho-1 gene transcription [39]. Cytoplasmic Nrf2 is bound to the Kelch-like ECHassociated protein 1 under general conditions; however, the Nrf2/ Keap1 complex can be disrupted by somecompounds, which allows the translocation of Nrf2 into the nuclei [40]. Previously, we reported that PV can activate the Nrf2/HO-1 pathway to defend against lipopolysaccharide 


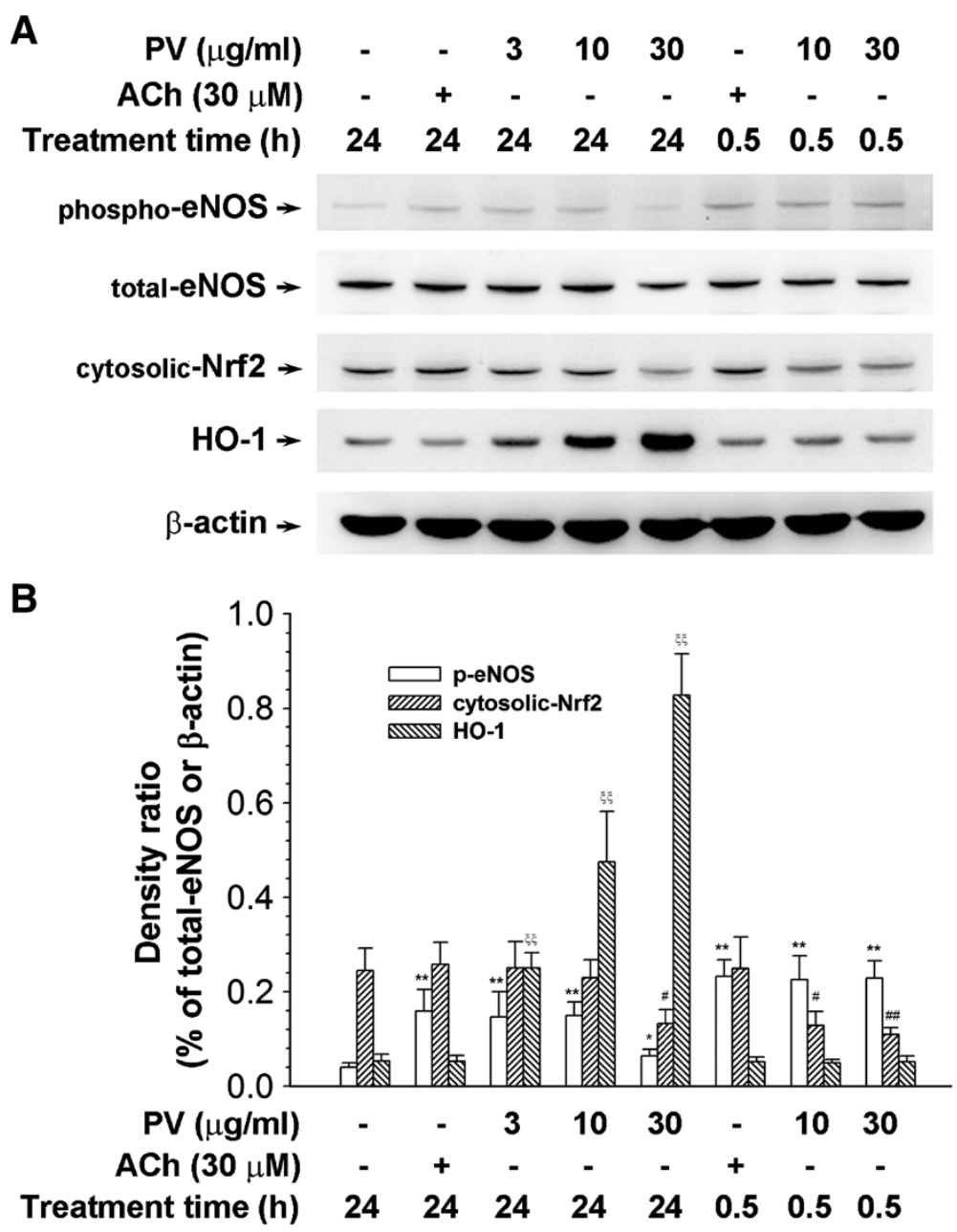

Figure 4 Effect of Polygonum viviparum (PV) on endothelial nitric oxide (NO) synthase (eNOS) phosphorylation, cytosolic nuclear factor E2-related factor 2 (Nrf2) degradation, and heme oxygenase (HO)-1 activation. (A) Human umbilical vein endothelial cells (HUVECs) were treated with PV (at the indicated concentrations) for 0.5 or $24 \mathrm{~h}$. Total proteins $(30 \mu \mathrm{g})$ were analyzed on an 8\% SDS-PAGE with an antibody specific of eNOS Ser-1177; and analyzed on 10\% SDS-PAGE with an antibody specific of Nrf2 and HO-1. (B) The relative density was calculated as the ratio of eNOS (phosphor form) expression to eNOS (total form) expression. In addition, the relative density was calculated as the ratio of Nrf2 degradation and HO-1 expression to $\beta$-actin expression. Each electrophoretogram is representative of the results from more than 5 individual experiments. ${ }^{*} p<0.05,{ }^{\#} p<0.05,{ }^{\xi \xi} p<0.01$, significantly different from the control.

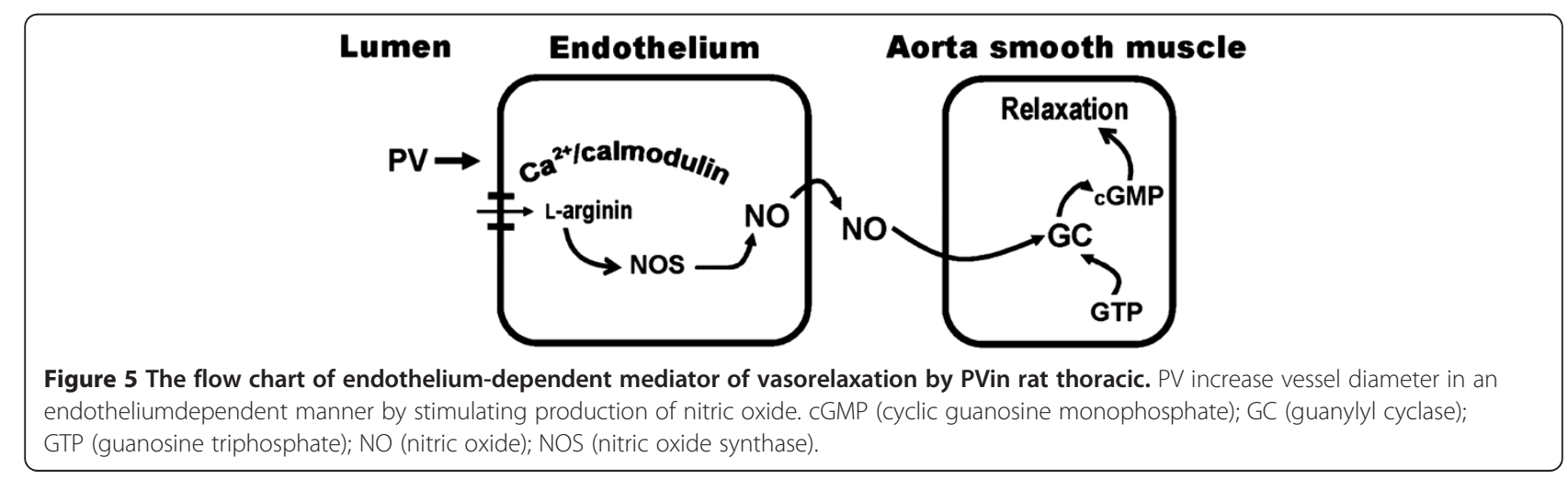


(LPS)-induced macrophage inflammation [4]. Now, we provide evidence that PV can induce Nfr2 activation and further promote eNOS phosphorylation by HUVECs. In the context of the cardiovascular system, knowledge that Nrf2 possesses antioxidant and anti-inflammatory characters can be of benefit in the onset of endothelial dysfunction [41]. Ideally, eNOS is sufficiently phosphorylated to produce NO, and it then has a protective physiological function and reaches its signaling target, mainly activating soluble guanylyl cyclase and eliciting cGMP production in the vasculature [42].

\section{Conclusions}

Results from this study showed that PV can relax PE precontractions in an endothelium-dependent manner in the rat aorta. The fact that activating $\mathrm{Ca}^{2+} /$ calmodulindependent NO synthesis signaling plays a critical role in the regulation of PV-induced vasorelaxation supports our results. Overall, we provide possible mechanistic insights of PV in an approach for therapy of vascular-associated disorders.

\section{Competing interests}

The authors declare that they have no competing interests.

\section{Authors' contributions}

MLC and JSC contributed equally to this work. MLC, JSC and CMH participated in the design and coordination of the study, carried out the analyses, and wrote the manuscript. WYY, KPC and JSL helped draft the manuscript and analyzed data for the statistical analysis. HWC supplied the sample and related information of Polygonum viviparum L. CMH participated in data interpretation and manuscript preparation. All authors read and approved the final manuscript.

\section{Acknowledgments}

This work was supported in part by a grant from Taipei Medical University, Taiwan (TMU98-AE1-B08 and 102TMU-TMUH-16) and the National Science Council, Taiwan (NSC99-2320-B-038-004-MY2 and NSC102-2320-B-038-013).

\section{Author details}

${ }^{1}$ Emergency Department, Taipei Medical University Hospital, 252 Wu-Xing Street, Taipei 110, Taiwan. ${ }^{2}$ School of Nutrition and Health Sciences, Taipei Medical University, Taipei, Taiwan. ${ }^{3}$ School of Pharmacy, College of Pharmacy, Taipei Medical University, Taipei, Taiwan. ${ }^{4}$ Department of General Medicine, School of Medicine, College of Medicine, Taipei, Taiwan. ${ }^{5}$ Medical University, 250 Wu-Xing Street, Taipei 110, Taiwan.

\section{Received: 21 September 2012 Accepted: 17 April 2014}

Published: 7 May 2014

\section{References}

1. Petersen PM: Variation of the population structure of Polygonum viviparum $\mathrm{L}$. in relation to certain environmental conditions. Meddelelser Gronland 1981, 4:3-19.

2. Law R, Cook RED, Manlove RJ: The ecology of flower and bulbil production in Polygonum viviparum. Nord J Bot 1983, 3:559-565.

3. Penskar MR: Special Plant Abstract for Polygonum viviparum (alpine bistort). Lansing, Ml: Michigan Natural Features Inventory; 2008:3.

4. Cheng HW, Lee KC, Cheah KP, Chang ML, Lin CW, Li JS, Yu WY, Liu ET, Hu CM: Polygonum viviparum L. inhibits the lipopolysaccharide-induced inflammatory response in RAW264.7 macrophages through heme oxygenase-1 induction and activation of the Nrf2 pathway. I Sci Food Agri 2013, 93(3):491-497.
5. Kirtikar RK, Basu DB: Indian Medicinal Plants. In International Book Distributor, 9/B, Rajpur Road, 1st floor, Dehradum 28001, India, Volume III. 2nd edition. 1987:2098-2099.

6. Moss R, Parkinson JA: The digestion of bulbils (Polygonum viviparum L.) and berries (Vaccinium myrtillus L. and Empetrum sp.) by captive ptamigan (Lagopus mutus). Br J Nutr 1975, 33:197-206.

7. Moody A, Diggle PK, Steingraeber DA: Developmental analysis of the evolutionary origin of vegetative propagules in Mimulus gemmiparus (Scrophulariaceae). Am J Bot 1999, 86:1512-1522.

8. uz-Zaman R, Akhtar MS, Khan MS: Protective effects of Polygonum viviparum $L$. root and its extracts against lipid-peroxidation induced by indomethacin in rats. Int J Pharmacol 2005, 1:324-328.

9. Li K, Shen X, Zheng S: Studies on the volatile constituents of Polygonum viviparum L. J Northwest Normal Univ (Nat Sci) 1999, 35:65-67.

10. Zheng S, Li K, Wang J, Shen T, Shen X: Two new flavone glycosides from Polygonum viviparum L. Indian J Chem 2001, 40B:167-169.

11. Wang $X H, M a C Y$ : Isolation and identification of the antibacterial principle in zhuyalio (Polygonum viviparum). Chung Ts'Ao Yao 1981, 12:22.

12. Que S, Zheng $S$, Ma X: Studies on the chemical constituents of Polygonum viviparum L. J Northwest Normal Univ (Nat Sci) 2003, 39:51-53.

13. Xu YL, Dong Q, Hu FZ: Simultaneous quantitative determination of viterxin, quercetin and quercitrin in Polygonum viviparum in Tibet Plateau by RP-HPLC. Nat Prod Res Dev 2011, 23:894-897.

14. Glele-Coefe J, Senet JM: Study of the influence of water soluble extracts on the growth of Entamoeba histolytica in axenic medium in vitro. Plant Med Phytother 1982, 16:122-128.

15. Chen S: Pharmacognostical identification on the Chinese drug quanshen. Zhong Yao Cai 1997, 20:122-126.

16. Zhang CX XJD, Hu FZ: Optimization of extract technology of total favonoids in fruit of Polygonum viviparum L. by orthogonal experiment. Chi Phar 2008, 19:186-188.

17. Tan $P$, Yao LF, CX P: Mic test on test on 40 species of Qi herbs from Mt. Qingling. Lishizhen Med Mat Med Res 2005, 18:33-35.

18. Chen SJ, Ma KS, Zhong GY: Studies on the resisting action to the superoxide by Polygonum viviparum L. Southwest Agric Univ 2005, 18:33-36.

19. Herbs with anti-cancer capacity. http://www.patentstorm.us/applications/ 20050025841/fulltext.html.

20. Singh S, Sharma R, Singh G, Koul A, Khajuria A, Gupta VK, Koul P: Antiinflammatory and anti-arthritic activity of the rhizome extract of Polygonum viviparum L. Spatula DD 2011, 1:225-232.

21. Zhang CX, Li YL, Hu FZ: Studies on the chemical constituents from herba Polygonum viviparum L. Nat Prod Res Dev 2005, 17:177-178.

22. Hu CM, Cheng HW, Cheng YW, Kang JJ: Mechanisms underlying the induction of vasorelaxation in rat thoracic aorta by sanguinarine. Jpn $J$ Pharmacol 2001, 85:47-53.

23. Kauffman RF, Schenck KW, Utterback BG, Crowe VG, Cohen ML: In vitro vascular relaxation by new inotropic agents: relationship to phosphodiesterase inhibition and cyclic nucleotides. J Pharmacol Exp Ther 1987, 242:864-872.

24. Lowry OH, Rosebrough NJ, Farr AL, Randall RJ: Protein measurement with the folin phenol reagent. J Biol Chem 1951, 193:265-275.

25. Florian M, Lu Y, Angle M, Magder S: Estrogen induced changes in Aktdependent activation of endothelial nitric oxide synthase and vasodilation. Steroids 2004, 69:637-645.

26. Hu CM, Liu YH, Cheah KP, Li JS, Lam CSK, Yu WY, Choy CS: Heme oxygenase-1 mediates the inhibitory actions of brazilin in RAW264.7 macrophages stimulated with lipopolysaccharide. J Ethnopharmacol 2009, 121:79-85.

27. Bradford MM: Arapid and sensitive method for the quantitation of microgram quantities of protein utilizing the principle of protein-dye binding. Anal Biochem 1976, 72:248-254.

28. Al-Zobaidy MJ, Craig J, Brown K, Pettifor G, Martin W: Stimulus-specific blockade of nitric oxide-mediated dilatation by asymmetric dimethylarginine (ADMA) and monomethylarginine (L-NMMA) in rat aorta and carotid artery. Eur J Pharmacol 2011, 673:78-84.

29. Furchgott RF, Zawadzki JV: The obligatory role of endothelial cells in the relaxation of arterial smooth muscle by acetylcholine. Nature 1980, 288:373-376.

30. Palmer RM, Ferrige AG, Moncada S: Nitric oxide release accounts for the biological activity of endothelium-derived relaxing factor. Nature 1987, 327:524-526. 
31. Palmer RM, Ashton DS, Moncada S: Vascular endothelial cells synthesize nitric oxide from L-arginine. Nature 1988, 333:664-666.

32. Evora PR, Evora PM, Celotto AC, Rodrigues AJ, Joviliano EE: Cardiovascular therapeutics targets on the NO-sGC-cGMP signaling pathway: a critical overview. Curr Drug Targets 2012, 13:1207-1214.

33. Ogden JE, Moore PK: Inhibition of nitric oxide synthase-potential for a novel class of therapeutic agent? Trends Biotechnol 1995, 13:70-78.

34. Deem S: Nitric oxide scavenging by hemoglobin regulates hypoxic pulmonary vasoconstriction. Free Radic Biol Med 2004, 36:698-706.

35. Schmidt HH, Lohmann SM, Walter U: The nitric oxide and cGMP signal transduction system: regulation and mechanism of action. Biochim Biophys Acta 1993, 1178:153-175.

36. Rafikov R, Fonseca FV, Kumar S, Pardo D, Darragh C, Elms S, Fulton D, Black SM: eNOS activation and NO function: structural motifs responsible for the posttranslational control of endothelial nitric oxide synthase activity. J Endocrinol 2011, 210:271-284.

37. Fulton D, Ruan L, Sood SG, Li C, Zhang Q, Venema RC: Agonist stimulated endothelial nitric oxide synthase activation and vascular relaxation. Role of eNOS phosphorylation at Tyr83. Circ Res 2008, 102:497-504.

38. Heiss EH, Schachner D, Werner ER, Dirsch VM: Active NF-E2-related factor (Nrf2) contributes to keep endothelial NO synthase (eNOS) in the coupled state: role of reactive oxygen species (ROS), eNOS, and heme oxygenase (HO-1) levels. J Biol Chem 2009, 284:31579-31586.

39. Pae HO, Chung HT: Heme oxygenase-1: its therapeutic roles in inflammatory diseases. Immune Netw 2009, 9:12-19.

40. Juge N, Mithen RF, Traka M: Molecular basis for chemoprevention by sulforaphane: a comprehensive review. Cell Mol Life Sci 2007, 64:1105-1127.

41. Zhang C: The role of inflammatory cytokines in endothelial dysfunction. Basic Res Cardiol 2008, 103:308-406.

42. Braam B, Verhaar MC: Understanding eNOS for pharmacological modulation of endothelial function: a translational view. Curr Pharm Des 2007, 13:1727-1740.

doi:10.1186/1472-6882-14-150

Cite this article as: Chang et al:: Polygonum viviparum $L$. induces vasorelaxation in the rat thoracic aorta via activation of nitric oxide synthase in endothelial cells. BMC Complementary and Alternative Medicine 2014 14:150

\section{Submit your next manuscript to BioMed Central and take full advantage of:}

- Convenient online submission

- Thorough peer review

- No space constraints or color figure charges

- Immediate publication on acceptance

- Inclusion in PubMed, CAS, Scopus and Google Scholar

- Research which is freely available for redistribution 